\title{
Effect of Single and Multiple Courses of Prenatal Corticosteroids on 17-Hydroxyprogesterone Levels: Implication for Neonatal Screening of Congenital Adrenal Hyperplasia
}

\author{
FRÉDÉRIQUE GATELAIS, JACQUES BERTHELOT, FRÉDÉRIQUE BERINGUE, \\ PHILIPPE DESCAMPS, DOMINIQUE BONNEAU, JEAN-MARIE LIMAL, AND RÉGIS COUTANT \\ Departments of Pediatrics [F.G., F.B., J.M.L., R.C.], Genetics [J.B., D.B.], and Obstetrics and \\ Gynecology [P.D.], University Hospital, 49000 Angers, France
}

\begin{abstract}
Measurement of 17-hydroxyprogesterone (17-OHP) from filter-paper blood is widely used to screen for congenital adrenal hyperplasia $(\mathrm{CAH})$. However, in pregnancies with an expected preterm delivery, prenatal treatment with steroids to induce pulmonary maturation could suppress the fetal adrenals and interfere with this screening. In 160 infants who were born between 25 and 35 wk of gestation, we measured 17-OHP in filter-paper blood at 72-96 $\mathrm{h}$ and compared the values between those who had not received antenatal steroids $(n=50)$ and those who had $(n=110)$. A single course of steroids was two 12-mg injections of betamethasone given within a 24-h interval: 30 infants received a half single course, 45 received a full single course, and 35 received multiple courses. Results are expressed as medians (25th percentile; 75th percentile). Blood 17-OHP differed significantly among groups: $23.7(14.2 ; 30.7) \mathrm{nmol} / \mathrm{L}$, $26.1(15.0 ; 50.1) \mathrm{nmol} / \mathrm{L}, 20.1(13.8 ; 29.1) \mathrm{nmol} / \mathrm{L}$, and 14.9 $(9.5 ; 26.2) \mathrm{nmol} / \mathrm{L}$ (for, respectively, no steroid, half a single course, a full single course, and multiple courses; $p<0.05$,
\end{abstract}

\section{ABSTRACT}

multiple comparisons with the Kruskal-Wallis test). However, only infants who were treated with multiple antenatal courses of steroids had lower blood 17-OHP than those who were untreated ( $p<0.05$ with the Mann-Whitney $U$ test). In multiple regression analysis, steroid treatment and intrauterine growth retardation were significant negative predictors of blood 17-OHP, whereas respiratory distress syndrome was a significant positive predictor (multiple $R=0.50, p<0.001$ ). Multiple courses of steroids in preterm infants decrease 17-OHP values by $\sim 30 \%$ in filter-paper blood, thus raising the risk of false-negative results in screening programs for CAH. (Pediatr Res 56: 701-705, 2004)

\section{Abbreviations}

CAH, congenital adrenal hyperplasia

IUGR, intrauterine growth retardation

RDS, respiratory distress syndrome

17-OHP, 17-hydroxyprogesterone
Congenital adrenal hyperplasia (CAH) is a family of recessive inherited disorders caused by a defect in one of the enzymes necessary for cortisol synthesis in the adrenal cortex. More than $90 \%$ of all cases are caused by 21-hydroxylase deficiency (1). The most severe forms of $\mathrm{CAH}$ lead to a salt-wasting crisis from a lack of both glucocorticoids and mineralocorticoids, usually during the first weeks of life (1). Because the severe forms of CAH can be rapidly fatal, rapid diagnosis and intervention in the newborn are critical. An elevated blood level of 17-hydroxyprogesterone (17-OHP) is used as an indicator of $\mathrm{CAH}$, and since the development of a technique for measuring 17-OHP in filter-paper blood samples, screening programs for $\mathrm{CAH}$ have been introduced in several

Received September 11, 2003; accepted February 9, 2004.

Correspondence: Régis Coutant, M.D., Department of Pediatrics, University Hospital,

15 Rue Larrey, 49000 Angers, France; E-mail: recoutant@chu-angers.fr

DOI: 10.1203/01.PDR.0000142733.50918.6E countries (2-4). France started in 1985 a screening program that became nationwide in 1997. The prevalence of CAH in the French population was calculated to be $1 / 15,956$ (5).

Normal ranges of 17-OHP depend on gestational age and are higher for preterm newborns (6-11). Consequently, one of the major problems encountered in screening programs is the high incidence of false-positive results in preterm infants. To reduce this rate, gestational age-related recall levels of 17-OHP have been proposed $(1,7,8,10,12)$. However, the situation is now even more complex because prenatal treatment with glucocorticoids has become a usual means to induce pulmonary maturation in pregnancies with an expected preterm delivery $(13,14)$.

The efficacy of antenatal corticosteroids in decreasing the rate of respiratory distress syndrome, intraventricular hemorrhage, and neonatal mortality has been demonstrated in numerous randomized, controlled trials (14). In 1994, a consensus 
statement on the benefits of antenatal corticosteroids for fetal maturation was published by the National Institutes of Health, recommending that a single course of corticosteroids be given between 24 and $34 \mathrm{wk}$ of gestation to all women who are at risk of preterm delivery within $7 \mathrm{~d}$ (14). The preferred antenatal treatment is betamethasone given as an initial 12-mg maternal injection at the identification of preterm delivery risk and then again $24 \mathrm{~h}$ later. Because of the alleged loss of efficacy after $7 \mathrm{~d}$, weekly repeated courses of antenatal glucocorticoids have become a common practice. However, the benefit of this policy was recently questioned $(15,16)$, because repeated antenatal doses of steroids may decrease birth weight and alter brain development [reviewed in (16)] with no demonstrated benefit to neonatal outcome (17).

One of the potential "adverse events" of antenatal corticosteroid administration is its interference with screening programs for $\mathrm{CAH}$, because corticosteroids are known to suppress the hypothalamic-pituitary-adrenal axis. Prenatal treatment with dexamethasone has efficiently suppressed fetal adrenal function and prevented or reduced virilization in female individuals who have CAH (1,18-22). Because betamethasone and dexamethasone have a similar ability to cross the placenta and suppress the fetal pituitary-adrenal axis, the use of antenatal corticosteroids bears a risk for decreasing blood-spot 17-OHP levels, thus leading to false-negative results.

To address this issue, we measured 17-OHP levels in filterpaper blood samples that were obtained 72-96 h after birth in 160 premature infants who were born between the 25th and 35 th weeks of gestation. Values were compared between infants whose mothers did not receive glucocorticoids $(n=50)$ and those whose mothers received a half single course of betamethasone (12 mg; $n=30)$, a full single course of betamethasone ( $24 \mathrm{mg} ; n=45$ ), or multiple courses of betamethasone ( $\geq 48 \mathrm{mg} ; n=35$ ). We also studied the effects of possible interfering factors, such as gestational age, mode of delivery, Apgar score, respiratory distress syndrome, and neonatal sepsis.

\section{METHODS}

Patients. We studied 160 premature infants who had gestational ages of 25-35 wk and were born in the Department of Obstetrics and Gynecology of Angers University Hospital between January 2001 and January 2003 and subsequently admitted to the neonatal intensive care unit of the hospital. Newborn gestational age was determined using ultrasonographic criteria from early $(\leq 12 \mathrm{wk})$ ultrasound scans. The main causes of preterm birth were preeclampsia, premature rupture of the membranes, intrauterine growth retardation (IUGR), chorioamnionitis, and vaginal bleeding (placenta praevia or placental abruption). The infants were assigned to one of four groups on the basis of antenatal treatment: 50 infants were without antenatal treatment because of immediate delivery on admission to the Department of Obstetrics; 30 infants had mothers who received half a single course of betamethasone $(12 \mathrm{mg}$ of betamethasone i.m.) because of delivery soon after the first injection; 45 had mothers who received a full single course (12 $\mathrm{mg}$ of betamethasone i.m., repeated $24 \mathrm{~h}$ later); and 35 infants had mothers who received multiple courses of glucocorticoids; that is, a full course of betamethasone with another course repeated $7 \mathrm{~d}$ later ( $48 \mathrm{mg}$ of betamethasone; $n=32$ ), or 7 and $14 \mathrm{~d}$ later ( $72 \mathrm{mg}$ of betamethasone; $n=3$ ). Infants who were from multiple pregnancies, had malformative syndrome, or had mothers who had received glucocorticoids for reasons other than preterm delivery risk were excluded. Infants with partial records (i.e. pregnancies that were not completely followed at the Department of Obstetrics and Gynecology of Angers University Hospital or with no early ultrasound scan) were also excluded.

Body weight and length and head circumference were recorded. The percentile for birth weight was calculated according to the standard French growth curves of Leroy (23). IUGR was defined as a birth weight below the 10th percentile of normal values. Identified causes of IUGR were maternal hypertension and maternal smoking, found in 24 and $30 \%$ of mothers, respectively, with no difference among glucocorticoid treatment groups.

Mode of delivery (vaginal or cesarean section), Apgar score, respiratory distress syndrome, and neonatal sepsis occurring before $96 \mathrm{~h}$ after birth were recorded as events potentially influencing the 17-OHP value. Respiratory distress syndrome (RDS) was defined as the need for mechanical ventilation with supplemental oxygen for at least $48 \mathrm{~h}$ or the administration of exogenous surfactant and typical findings on chest $\mathrm{x}$-ray film (reticulogranular pattern in the lungs with air bronchograms). The time from the last glucocorticoid dose to the day of sampling was recorded. This study was approved by the ethics committee of the University of Angers. All families gave their informed consent.

Neonatal screening for $\boldsymbol{C A H}$. Filter-paper blood spots collected between 72 and $96 \mathrm{~h}$ after birth were used. 17-OHP was analyzed using fluoroimmunoassay (Autodelfia 17-OHP; PerkinElmer Life Sciences, Wallac Oy, Turku, Finland). The inter- and intra-assay coefficients of variation were 5-12\% and $8-12 \%$, respectively. The cut-off limit in the French neonatal screening program for a positive test is $60 \mathrm{nmol} / \mathrm{L}$.

Statistical analysis. Blood 17-OHP was not normally distributed, as assessed by the Komolgorov-Smirnov test. Therefore, the results are presented as medians (25th percentile; 75th percentile), and Kruskal-Wallis and Mann-Whitney $U$ tests (nonparametric tests) were used for comparisons among groups. Blood 17-OHP was log transformed to normalize its distribution, and simple regression analyses were performed with blood 17-OHP as the dependent variable. To determine the best combination of predictors of blood 17-OHP level, we then performed multiple regression analyses, using significant variables in simple regression analysis. Significance was defined as $p<0.05$. All analyses were two-tailed and performed with the SPSS 9.0.1 statistical package.

\section{RESULTS}

Clinical characteristics of the infants. The clinical characteristics of mothers and newborns are indicated in Table 1. The four groups were comparable for maternal age, gestation num- 
Table 1. Clinical characteristics in the four groups according to antenatal corticosteroid treatment

\begin{tabular}{|c|c|c|c|c|c|}
\hline & $\begin{array}{l}\text { No antenatal } \\
\text { treatment }\end{array}$ & $\begin{array}{l}\text { Half single } \\
\text { course }\end{array}$ & $\begin{array}{l}\text { Full single } \\
\text { course }\end{array}$ & Multiple courses & $p$ \\
\hline$N$ & 50 & 30 & 45 & 35 & \\
\hline Maternal age $(y)^{*}$ & $30(25.5 ; 32.0)$ & $29.0(24.5 ; 31.0)$ & $27.0(26.0 ; 31.0)$ & $28.0(26.7 ; 30.2)$ & NS \\
\hline Gestation number $(n)^{*}$ & $2(1 ; 3)$ & $2(1 ; 3)$ & $2(1 ; 3)$ & $2(1 ; 3)$ & NS \\
\hline Gestational age (wk)* & $33.6(31.3 ; 34.3)$ & $32.0(30.1 ; 33.4)$ & $32.4(29.9 ; 33.4)$ & $33.2(31.4 ; 34.1)$ & NS \\
\hline Gender $(\mathrm{M} / \mathrm{F})$ & $28 / 22$ & $16 / 14$ & $26 / 19$ & $17 / 18$ & NS \\
\hline Birth weight $(\mathrm{kg})^{*}$ & $1.94(1.33 ; 2.32)$ & $1.60(1.33 ; 2.11)$ & $1.65(1.13 ; 1.90)$ & $1.79(1.36 ; 2.01)$ & 0.05 \\
\hline Birth length $(\mathrm{cm})^{*}$ & $43.5(37.5 ; 45.0)$ & $42.0(39.5 ; 44.0)$ & $41.0(38.0 ; 44.0)$ & $42.0(39.8 ; 44.1)$ & NS \\
\hline Head circumference $(\mathrm{cm})^{*}$ & $31.0(28.0 ; 32.0)$ & $29.5(27.0 ; 31.0)$ & $29.0(27.0 ; 31.0)$ & $30.5(28.0 ; 32.0)$ & NS \\
\hline Apgar score $(1 \mathrm{~min}) *$ & $9(6 ; 10)$ & $8(3 ; 10)$ & $9(6 ; 10)$ & $9(8 ; 10)$ & NS \\
\hline $\operatorname{RDS}(\%)$ & $36 \%$ & $48 \%$ & $28 \%$ & $21 \%$ & 0.08 \\
\hline IUGR $(\%)$ & $24 \%$ & $32 \%$ & $31 \%$ & $37 \%$ & NS \\
\hline Neonatal sepsis $(\%)$ & $16 \%$ & $8 \%$ & $14 \%$ & $8 \%$ & NS \\
\hline Time interval between last dose and sampling (d) & & $3.7(3.0 ; 6.6)$ & $6.2(5.0 ; 7.9)$ & $14.9(6.2 ; 23.9)$ & $<0.0001$ \\
\hline
\end{tabular}

Multiple comparisons with the Kruskal-Wallis test; NS, nonsignificant.

* Data are median (25th; 75th percentiles).

ber, gestational age, newborn gender, birth weight and length, newborn head circumference, Apgar score, and percentages of IUGR and neonatal sepsis. There was a nonsignificant trend toward a lower percentage of RDS in infants whose mothers had received a full single course or multiple courses of betamethasone, compared with those whose mothers received no corticosteroids $(p=0.08)$. The frequencies of the main causes of preterm birth (detailed in "Methods") were similar in the four groups (data not shown).

Blood 17-OHP levels according to glucocorticoid treatment. Blood 17-OHP was similar between children who received no antenatal steroid treatment and those who received it [23.7 $(14.2 ; 30.6) \mathrm{nmol} / \mathrm{L}$ versus $19.5(12.7 ; 31.5) \mathrm{nmol} / \mathrm{L} ; p>$ 0.05]. However, a significant difference was noted when the infants were considered in terms of number of treatment courses $[23.7(14.2 ; 30.6) \mathrm{nmol} / \mathrm{L}, 26.1(15.0 ; 50.1) \mathrm{nmol} / \mathrm{L}$, $20.1(13.8 ; 29.1) \mathrm{nmol} / \mathrm{L}$, and $14.9(9.5 ; 26.2) \mathrm{nmol} / \mathrm{L}$, respectively, no corticosteroid, half a single course of betamethasone, a full single course, and multiple courses; $p<0.05$, KruskalWallis test]. This difference remained significant even after exclusion of infants with IUGR and/or neonatal sepsis. The difference in blood 17-OHP levels was also expressed through the significant negative correlation between blood 17-OHP and the cumulative betamethasone dose $(r=-0.19, p<0.05$; Table 2). Consistently, a decrease in the upper limit of 17-OHP according to the number of glucocorticoid courses was observed, because the 95th percentile of 17-OHP was 66, 71, 49, and $48 \mathrm{nmol} / \mathrm{L}$ for, respectively, no steroid, half a single course, a full single course, and multiple courses.

For further studying the differences in 17-OHP values among groups, Mann-Whitney $U$ tests were performed for comparison between two groups. The difference between groups was in fact restricted to the infants whose mothers had received multiple courses of betamethasone and those without antenatal treatment ( $p<0.05$ with the Mann-Whitney $U$ test). There was no difference between the groups whose mothers had received a complete or incomplete single course of betamethasone and those who were untreated. Overall, these results suggest that multiple courses of corticosteroids decrease blood $17-$ OHP by $\sim 30 \%$.
Similar trends in blood 17-OHP values were observed for only those infants who were born with IUGR and only those with RDS (i.e. a decrease in blood 17-OHP in the infants who had received multiple courses of glucocorticoid compared with those who received no antenatal steroid), although these differences did not reach significance, likely because of the smaller size of these groups.

Blood 17-OHP according to gestational age and birth weight. Blood 17-OHP was significantly different according to gestational age $[41(26 ; 62) \mathrm{nmol} / \mathrm{L}, 25(16 ; 38) \mathrm{nmol} / \mathrm{L}, 23$ $(14 ; 32) \mathrm{nmol} / \mathrm{L}$, and $16(11 ; 23) \mathrm{nmol} / \mathrm{L}$, respectively, gestational age $\leq 28 \mathrm{wk}, 29-31 \mathrm{wk}, 32-33 \mathrm{wk}$, and $>33 \mathrm{wk} ; p<$ 0.01 , Kruskal-Wallis test]. Conversely, it did not differ according to birth weight $[27(13 ; 50) \mathrm{nmol} / \mathrm{L}, 20(11 ; 28) \mathrm{nmol} / \mathrm{L}, 22$ $(14 ; 32) \mathrm{nmol} / \mathrm{L}$, and $18(14 ; 28) \mathrm{nmol} / \mathrm{L}$, respectively, birth weight $<1.000 \mathrm{~kg}, 1.000-1.499 \mathrm{~kg}, 1.500-1.999 \mathrm{~kg}$, and $\geq 2.000 \mathrm{~kg}$; NS, Kruskal-Wallis test).

Determinants for blood 17-OHP by regression analysis. To study further the other potential influences on blood 17-OHP levels, we then performed simple regression analyses between blood 17-OHP (after log transformation to normalize its distribution; see "Methods") and other variables (Table 2). Corticosteroid treatment, gestational age, mode of delivery (vaginal $=0$, cesarean $=1$, presence of IUGR, and time interval between last dose and sampling were negatively correlated with blood 17-OHP values, whereas the presence of RDS was positively correlated with these values.

As shown in simple regression analyses, several variables may influence 17-OHP levels, and some may be confounding factors. To select the best combination of independent predictors of blood 17-OHP, we finally entered all of the variables that were significantly related to blood $17-\mathrm{OHP}$ in simple regression analyses into multiple regression analyses. Corticosteroid treatment $(0=$ no; $1=$ half a single course; $2=$ a full single course; $3=$ multiple courses; $\beta=-0.13, p=0.01)$ and the presence of IUGR $(0=$ no; $1=$ yes; $\beta=-0.22, p=0.01)$ were significant and independent negative predictors of blood 17-OHP, whereas the presence of RDS $(0=$ no; $1=$ yes; $\beta=$ $0.22, p=0.01$ ) was a significant positive predictor (multiple $R$ $=0.50, p<0.0001)$. Gestational age, mode of delivery, and 
Table 2. Significant simple regression analyses between 17-OHP and other variables

\begin{tabular}{lcc}
\hline \multicolumn{1}{c}{ Blood 17-OHP* } & $r$ & $p$ \\
\hline Corticosteroid group & -0.19 & $<0.05$ \\
$0=$ no; 1 = half a single course; & & \\
2 = a full single course; $3=$ multiple courses & & \\
Gestational age & -0.22 & $<0.001$ \\
Mode of delivery $(0=$ vaginal; $1=$ cesarean $)$ & -0.16 & 0.06 \\
IUGR $(0=$ no; $1=$ yes $)$ & -0.30 & $<0.0001$ \\
Time interval between last dose and sampling & -0.24 & $<0.05$ \\
RDS $(0=$ no; $1=$ yes $)$ & 0.33 & $<0.0001$ \\
\hline
\end{tabular}

Blood 17-OHP was log transformed before analysis. Maternal age, gestation number, gestational age, corticosteroid group, mode of delivery, time interval between last dose and sampling, Apgar score, neonatal sepsis, IUGR, and RDS were entered as independent variables in the simple regression analyses. Only significant or borderline significant correlations are presented.

time interval between last dose and sampling were no longer significant predictors of 17-OHP values but were kept in the regression analysis as adjusting factors.

\section{DISCUSSION}

We showed that antenatal glucocorticoid therapy decreased blood-spot 17-OHP values. However, this effect was seen only for repeated courses of glucocorticoid, whereas a single course had no detectable effect. On average, blood 17-OHP was $~ 30 \%$ lower in infants whose mothers had received multiple courses of betamethasone compared with infants whose mothers had received a single course or no betamethasone. These differences were still observed after exclusion of infants with IUGR or neonatal sepsis. In multiple regression analysis, steroid courses, IUGR, and RDS were significant independent predictors of 17-OHP levels in this population of premature newborns. The administration of multiple courses of antenatal corticosteroid could interfere with screening programs for CAH: it may lead to the theoretical risk of false-negative results and should be taken into account for the interpretation of blood-spot 17-OHP values.

As a whole, the group of premature newborns whose mothers had received steroids had blood-spot 17-OHP levels similar to those whose mothers had not. This agrees with the studies of King et al. (24) and Nordenström et al. (10), who found no influence of glucocorticoid use on blood-spot 17-OHP values. However, neither the number of antenatal steroid courses nor the dose was specified in these studies; thus, they were not taken into account. In our study, the infants with antenatal glucocorticoid treatment could be divided into three groups with at least 30 infants per group: those whose mothers had received half a single course of betamethasone (12 mg within $24 \mathrm{~h}$ before birth), a full single course $(2 \times 12 \mathrm{mg}$ with a 24 -h interval), or repeated courses of betamethasone $(48 \mathrm{mg}$ or more; i.e. a full course repeated $7 \mathrm{~d}$ later or 7 and $14 \mathrm{~d}$ later). By doing so, we observed a significant difference in blood-spot 17-OHP concentration among groups, whereas other potentially influential variables (gestational age, infectious disease, RDS, and so on) were similar. Several studies of the impact of antenatal corticosteroids on adrenal function, totaling $>200$ premature infants, have shown that antenatal therapy decreases blood cortisol and dehydroepiandrosterone sulfate by $~ 50 \%$ for
$7 \mathrm{~d}$ after birth $(25,26)$. Overall, these results suggest that our observation of an impact of antenatal corticosteroid on blood 17-OHP should not be surprising, although this impact was dependent on the cumulative dose and/or the number of courses of betamethasone.

Several hypotheses could explain the impact of antenatal steroids on blood-spot 17-OHP levels. First, a glucocorticoid effect might be apparent only at a cumulative threshold dose of $48 \mathrm{mg}$ of betamethasone. In studies of antenatal treatment of female fetuses with congenital adrenal hyperplasia, it has been shown that fetal adrenals are efficiently suppressed by daily dexamethasone doses as low as $1-1.5 \mathrm{mg}$, corresponding to a cumulative dose of $14-21 \mathrm{mg}$ for $2 \mathrm{wk}(1,18-22)$. Because betamethasone and dexamethasone have similar potencies, 24 $\mathrm{mg}$ of betamethasone repeated $7 \mathrm{~d}$ apart (i.e. two full courses), corresponding to $48 \mathrm{mg}$ for $2 \mathrm{wk}$, is roughly equivalent to a 2-3 times higher dose, which would likely be suppressive. Alternatively, because gestational age at birth was similar in all groups of premature infants, fetuses who were exposed to multiple courses of glucocorticoid were also younger at the onset of treatment, and the adrenals as well as pituitary could be more sensitive to the glucocorticoid suppressive effect at a lower gestational age. The steroid profiles in preterm infants suggest a functional deficiency of several adrenal steroidogenic enzymes, including 21-hydroxylase, with a nadir in function at $29 \mathrm{wk}$ of gestation (27).

Surprising, the time interval between the last dose and sampling was negatively correlated with blood-spot 17-OHP in this study. However, the infants in whom the longer time interval between last dose and sampling was seen were also the youngest at the onset of administration and those who had received the highest cumulative betamethasone doses. We thus believe that the apparent negative effect of time interval on blood-spot 17-OHP reflects the higher betamethasone doses administered to these infants. Time interval was not significantly related to 17-OHP level in multiple regression analyses.

Gestational age was negatively correlated with blood-spot 17-OHP in simple regression analysis, in agreement with results from several other studies (2,28-31). Elevated 17-OHP levels in preterm infants have been confirmed by HPLC and thus are not due only to overestimation by fluoroimmunoassays (8) or cross-reaction with other steroids (32). However, the extraction procedure failed to improve the sensitivity and specificity of the screening (10).

In addition to glucocorticoid treatment, IUGR and RDS were significant independent predictors of blood-spot 17-OHP in multiple regression analysis, in agreement with other studies $(11,28,33)$ : positive relationships between birth weight SD score and basal and stimulated blood 17-OHP were recently reported in 43 premature infants with and without growth retardation, suggesting that adrenal function was related to fetal growth in preterm infants (33). The positive influence of RDS on blood 17-OHP has also been previously described in other studies (28) and is usually viewed as a consequence of illness-related stress.

Because blood-spot 17-OHP is higher in premature infants than in term newborns, gestational age-related as well as weight-related recall levels of 17-OHP have been proposed 
$(1,7,8,10,12)$. Suggested cut-offs have ranged from 60 to 500 $\mathrm{nmol} / \mathrm{L}$, based on weight or gestational age (10,34-36). Given the high rate of false-positive results in premature infants, those with moderate elevations are often considered normal, although they require follow-up. Although most severe cases of CAH usually have extremely high levels of 17-OHP at birth, correlation of these levels with clinical phenotype is not absolute $(10,37)$. In view of our results, a moderate level of blood-spot 17-OHP in a premature infant who has received multiple courses of antenatal steroids should be the object of careful interpretation. Because antenatal glucocorticoids may suppress adrenal function for $\sim 1$ wk after birth $(25,26)$, a second screening test for $\mathrm{CAH}$ at $1-2$ wk of age could be recommended for these infants. Initially proposed to detect more cases of simple virilizing CAH in term newborns (35), this would be useful for premature infants, provided that salt loss is monitored carefully between the two screenings.

\section{CONCLUSION}

In conclusion, the administration of multiple courses of antenatal corticosteroid decreases blood-spot 17-OHP by $\sim 30 \%$ and could interfere with screening programs for $\mathrm{CAH}$.

\section{REFERENCES}

1. Speiser PW, White PC 2003 Congenital adrenal hyperplasia. N Engl J Med 349:776 788

2. Pang S, Hotchkiss J, Drash AL, Levine LS, New MI 1977 Microfilter paper method for 17 alpha-hydroxyprogesterone radioimmunoassay: its application for the rapid screening for congenital adrenal hyperplasia. J Clin Endocrinol Metab 45:1003-1008

3. Pang SY, Wallace MA, Hofman L, Thuline HC, Dorche C, Lyon IC, Dobbins RH, Kling S, Fujieda K, Suwa S 1988 Worldwide experience in newborn screening for classical congenital adrenal hyperplasia due to 21 -hydroxylase deficiency. Pediatrics $81: 866-874$

4. Pang S, Shook MK 1997 Current status of neonatal screening for congenital adrenal hyperplasia. Curr Opin Pediatr 9:419-423

5. Cartigny-Maciejewski M, Guilley N, Vanderbecken S, Gonde S, Stuckens C, Ponte C, Weill J, Farriaux JP, Paux E 1999 [Neonatal screening of congenital adrenal hyperplasia due to 21- hydroxylase deficiency: Lille experience 1980-1996]. Arch Pediatr 6:151-158

6. Döerr HG, Sippell WG, Versmold HT, Bidlingmaier F, Knorr D 1988 Plasma mineralocorticoids, glucocorticoids, and progestins in premature infants: longitudinal study during the first week of life. Pediatr Res 23:525-529

7. Allen DB, Farrell PM 1996 Newborn screening: principles and practice. Adv Pediatr 43:231-270

8. al Saedi S, Dean H, Dent W, Stockl E, Cronin C 1996 Screening for congenital adrenal hyperplasia: the Delfia Screening Test overestimates serum 17hydroxyprogesterone in preterm infants. Pediatrics 97:100-102

9. Lee MM, Rajagopalan L, Berg GJ, Moshang T Jr 1989 Serum adrenal steroid concentrations in premature infants. J Clin Endocrinol Metab 69:1133-1136

10. Nordenstrom A, Wedell A, Hagenfeldt L, Marcus C, Larsson A 2001 Neonatal screening for congenital adrenal hyperplasia: 17-hydroxyprogesterone levels and CYP21 genotypes in preterm infants. Pediatrics 108:E68

11. Linder N, Davidovitch N, Kogan A, Barzilai A, Kuint J, Mazkeret R, Sack J 1999 Longitudinal measurements of 17alpha-hydroxyprogesterone in premature infants during the first three months of life. Arch Dis Child Fetal Neonatal Ed 81:F175-F178

12. Pass KA, Lane PA, Fernhof PM, Hinton CF, Panny SR, Park JS, Pelias MZ, Rhead WJ, Ross SI, Wethers DL, Elsas LJ 2nd, for CORN 2000 US Newborn Screening
System Guidelines II: follow-up of children, diagnosis, management, and evaluation statement of the Council of Regional Networks for Genetic Services (CORN). J Pediatr 137:S1-S46

13. Liggins GC, Howie RN 1972 A controlled trial of antepartum glucocorticoid treatment for prevention of the respiratory distress syndrome in premature infants. Pediatrics 50:515-525

14. 1994 Effect of corticosteroids for fetal maturation on perinatal outcomes. NIH Consens Statement 12:1-24

15. 2001 Antenatal corticosteroids revisited: repeat courses-National Institutes of Health Consensus Development Conference Statement, August 17-18, 2000. Obstet Gynecol 98:144-150

16. Walfisch A, Hallak M, Mazor M 2001 Multiple courses of antenatal steroids: risks and benefits. Obstet Gynecol 98:491-497

17. Wijnberger LD, Mostert JM, van Dam KI, Mol BW, Brouwers H, Visser GH 2002 Comparison of single and repeated antenatal corticosteroid therapy to prevent neonatal death and morbidity in the preterm infant. Early Hum Dev 67:29-36

18. David M, Forest MG 1984 Prenatal treatment of congenital adrenal hyperplasia resulting from 21-hydroxylase deficiency. J Pediatr 105:799-803

19. Pang SY, Pollack MS, Marshall RN, Immken L 1990 Prenatal treatment of congenital adrenal hyperplasia due to 21-hydroxylase deficiency. N Engl J Med 322:111-115

20. Forest MG, Morel Y, David M 1998 Prenatal treatment of congenital adrenal hyperplasia. Trends Endocrinol Metab 9:284-289

21. New MI, Carlson A, Obeid J, Marshall I, Cabrera MS, Goseco A, Lin-Su K, Putnam AS, Wei JQ, Wilson RC 2001 Prenatal diagnosis for congenital adrenal hyperplasia in 532 pregnancies. J Clin Endocrinol Metab 86:5651-5657

22. Joint LWPES/ESPE CAH Working Group 2002 Consensus statement on 21hydroxylase deficiency from the Lawson Wilkins Pediatric Endocrine Society and the European Society for Paediatric Endocrinology. J Clin Endocrinol Metab 87:4048 4053

23. Leroy B, Lefort F 1971 [The weight and size of newborn infants at birth]. Rev Fr Gynecol Obstet 66:391-396

24. King JL, Naber JM, Hopkin RJ, Repaske DR, Bailey L, Leslie ND 2001 Antenatal corticosteroids and newborn screening for congenital adrenal hyperplasia. Arch Pediatr Adolesc Med 155:1038-1042

25. Ballard PL, Gluckman PD, Liggins GC, Kaplan SL, Grumbach MM 1980 Steroid and growth hormone levels in premature infants after prenatal betamethasone therapy to prevent respiratory distress syndrome. Pediatr Res 14:122-127

26. Kari MA, Raivio KO, Stenman UH, Voutilainen R 1996 Serum cortisol, dehydroepiandrosterone sulfate, and steroid-binding globulins in preterm neonates: effect of gestational age and dexamethasone therapy. Pediatr Res 40:319-324

27. Nomura S 1997 Immature adrenal steroidogenesis in preterm infants. Early Hum Dev 49:225-233

28. Murphy JF, Joyce BG, Dyas J, Hughes IA 1983 Plasma 17-hydroxyprogesterone concentrations in ill newborn infants. Arch Dis Child 58:532-534

29. Larsson A, Hagenfeldt L, von Dobeln U, Curstedt T, Gustafsson J, Svensson E 1988 Neonatal screening for congenital adrenal hyperplasia using 17- hydroxyprogesterone assay in filter paper blood spots. Horm Res 30:235-240

30. Shimozawa K, Matsumoto M, Okada K, Murata M, Tsuchiya Y, Kitagawa T 1988 Analysis of blood spot 17 alpha-hydroxyprogesterone concentration in neonates Horm Res 30:246-251

31. Knudtzon J, Markestad T, Aakvaag A, Bergsjo P 1991 Elevated 17-hydroxyprogesterone levels in premature infants. Acta Paediatr Scand 80:96-97

32. Lange-Kubini K, Zachmann M, Kempken B, Torresani T 199615 beta-hydroxylated steroids may be diagnostically misleading in confirming congenital adrenal hyperplasia suspected by a newborn screening programme. Eur J Pediatr 155:928-931

33. Bolt RJ, van Weissenbruch MM, Popp-Snijders C, Sweep CG, Lafeber HN, Delemarre-van de Waal HA 2002 Fetal growth and the function of the adrenal cortex in preterm infants. J Clin Endocrinol Metab 87:1194-1199

34. Allen DB, Hoffman GL, Fitzpatrick P, Laessig R, Maby S, Slyper A 1997 Improved precision of newborn screening for congenital adrenal hyperplasia using weightadjusted criteria for 17-hydroxyprogesterone levels. J Pediatr 130:128-133

35. Therrell BL Jr, Berenbaum SA, Manter-Kapanke V, Simmank J, Korman K, Prentice L, Gonzales J, Gunn S 1998 Results of screening 1.9 million Texas newborns for 21-hydroxylase-deficient congenital adrenal hyperplasia. Pediatrics 101:583-590

36. Ohkubo S, Shimozawa K, Matsumoto M, Kitagawa T 1992 Analysis of blood spot 17 alpha-hydroxyprogesterone concentration in premature infants-proposal for cut-off limits in screening for congenital adrenal hyperplasia. Acta Paediatr Jpn 34:126-133

37. Gudmundsson K, Majzoub JA, Bradwin G, Mandel S, Rifai N 1999 Virilising 21-hydroxylase deficiency: timing of newborn screening and confirmatory tests can be crucial. J Pediatr Endocrinol Metab 12:895-901 